\title{
EXTRAÇÕES E FRAGMENTOS NO DISCURSO LATINO- AMERICANO: ARQUIVO, LEITURA, PEDAGOGIA
} EXTRACTIONS AND FRAGMENTS IN LATIN AMERICAN Discourse: Archive, READING, PeDAGOGY

\author{
Vinícius Ximenes \\ ORCID 0000-0002-7584-3681
}

Universidade Federal Fluminense

Niterói, RJ, Brasil

\begin{abstract}
Resumo
Quando Silviano Santiago publica seu ensaio sobre a discursividade latino-americana na década de 1970, a conjuntura teórica e política está marcada por uma crítica do estruturalismo e pela formação de um bloco histórico que, na década seguinte, participaria do processo constituinte: início de um ciclo. A intenção deste artigo é repensar tal discursividade tendo em vista que a conjuntura de 2020 atualiza alguns daqueles debates vinculados à dependência geoeconômica. Passando pelo arquivo recente da Casa de Rui Barbosa e por poemas de Marília Garcia, Ana Estaregui e Priscilla Menezes, proponho interrogar uma relação entre modos de ler o arquivo e a terra, ou entre as pedagogias de leitura e as práticas extrativas. Nas trilhas dos debates de Santiago, lidas com Josefina Ludmer, podemos posicionar a emergência de um conceito ampliado de extração que permite pensar algumas variaçóes no discurso latino-americano.
\end{abstract}

Palavras-chave: discurso latino-americano, extrativismo, modos de ler, poesia contemporânea.

\begin{abstract}
When Silviano Santiago published his essay on Latin American discourse in the 1970s, the theoretical and political conjuncture was characterised by a critique of structuralism and the formation of a historical block that, in the following decade, would participate in the Brazilian constituent process: the start of a cycle. This article aims to rethink this discursivity taking into account that the context in 2020 is bringing back some of these old debates about geoeconomics dependencies. Along with the recent archives of the Casa de Rui Barbosa and some poems by Marília Garcia,
\end{abstract}

\section{Resumen}

Cuando Silviano Santiago publica su ensayo sobre la discursividad latinoamericana en la década de 1970 , la coyuntura teórica estaba marcada por una crítica política al estructuralismo y por la formación de un bloque histórico que, en la década siguiente, participa en el proceso constituyente: inicio de un ciclo. El intento de este artículo es repensar esa articulación de la discursividad, considerando que la coyuntura del 2020 actualiza algunos debates de aquel momento, alrededor de la dependencia geoeconómica. Con los archivos recientes de la Casa de Rui Barbosa y algunos 
Ana Estaregui and Priscilla Menezes, I seek to investigate a relation between the ways of reading archive and land, or between pedagogies and extractive practices. Following on from Silviano Santiago's debates, read with Josefina Ludmer, we may position the emergence of an expanded concept of extraction that allows us to think about some variations in Latin American discourse.

Keywords: Latin American discourse, extractivism, modes of reading, contemporary poetry. poemas de Marília García, Ana Estaregui y Priscilla Menezes, propongo interrogar una relación entre modos de leer el archivo y la tierra, o entre las pedagogías de lectura y las prácticas extractivas. En los restos de los debates de Santiago, leídos con Josefina Ludmer, podemos posicionar el surgimiento de un concepto ampliado de extracción que nos permite pensar algunas variaciones en el discurso latinoamericano.

Palabras-clave: discurso latinoamericano, extractivismo, modos de ler, poesía contemporánea.

en la sociedad se enfrentan muchos modos de leer J. Ludmer é complicada a tarefa de minerar o ouro do outro para enriquecimento da própria bolsa S. Santiago

\section{Situação em um terreno institucional} (ou o arquivo que logo somos) ${ }^{1}$

Uma pequena busca nos arquivos recentes da Fundaçáo Casa de Rui Barbosa nos leva aos registros de três colóquios que parecem ter pensado a habitação da terra, entre 2011 e 2014. O primeiro deles - Espiral Terra, mundo Brasil-foi organizado pela Rede Universidade Nômade, com apoio da Escola de Comunicação da UFRJ e da Fundação, propondo avaliar relaçóes entre cultura e políticas públicas em uma série de encontros ao longo de 2011.

\footnotetext{
1 Tive a oportunidade de apresentar algumas ideias iniciais deste texto no II Colóquio Habitar a Terra: poesia e latino-americanidade, na Casa de Rui Barbosa, em outubro de 2019. Sou grato ao convite feito por Celia Pedrosa e estendo o agradecimento a Luciana di Leone, Marcos Natali, Susana Scramim, Claudete Daflon, Izabela Leal, Raúl Antelo e Eduardo Losso, que consideraram algumas das tentativas de articulaçáo em seus comentários ao longo dos dois dias de colóquio. O texto tenta manter alguns traços da fala situada. Vale registrar que, no período que se estende desde o início de 2020 e que acompanha a redação, a Fundação passa por reformulaçôes, sob ameaça de extinção. Ver, p. ex., as manchetes de O Globo (08/01/2020): "Ex-presidente da Casa de Rui Barbosa diz que governo afastou diretores por desconfiança dos intelectuais"; G1 Rio (13/01/2020): "Manifestantes protestam contra mudanças na direção da Casa de Rui Barbosa, em Botafogo, Rio"; e Folha de São Paulo (09/07/2020): "Governo Federal dá parecer positivo para extinção da Fundação Casa de Rui Barbosa”.
} 
A metade inicial de seu título fazia referência à tese de livre-docência de Mauricio Salles Vasconcelos, que culmina lendo os poemas de Marcelo Ariel ambientados em Cubatão, uma literatura na periferia precarizada e racializada da Baixada Santista, sede do maior polo petroquímico da América Latina, marcada por desastres energéticos do extrativismo industrial. Interessada em uma poesia expansiva, a tese de Espiral terra convoca perspectivas transversais, como as de Édouard Glissant, Kostas Axelos ou a ecosofia de Félix Guattari, apresentada e discutida em maio de 1992 durante o colóquio Ecologias na UERJ, num gesto de antecipação crítica dos eventos oficiais da Eco-92/ Cúpula da Terra, que começaria no mês seguinte.

O segundo evento, terraTERRA, título extraído de um poema de Décio Pignatari, teve lugar na Casa em junho de 2012 como atividade autogestionada na programação da Cúpula dos Povos, encontro de movimentos sociais e sociedade civil que corria em contraponto à Rio+20 (ou seja: à memória da Eco-92), ocupando com centenas de tendas o Aterro do Flamengo para apresentar alternativas sistêmicas e discutir justiça ambiental, tentando manter acesa alguma chispa da agenda alter-globalização articulada nos encontros do Fórum Social Mundial. O colóquio foi coorganizado pela mesma Uninômade, pelo Núcleo de Antropologia Simétrica do Museu Nacional, pela linha de pesquisa em Filosofia e Questáo Ambiental da PUC-Rio e pelo grupo que orbita a editora Cultura e Barbárie. Falaram, entre outros, Flávia Cera, Déborah Danowski, Eduardo Viveiros de Castro, Giuseppe Cocco e novamente Mauricio S. Vasconcelos.

No seguinte mês de junho, essas falas se expandiam no ruído múltiplo e conflituoso de ruas e polícias, quando os arquivos abertos valeram como mecanismos de autodefesa, na proliferaçáo de mídias livres e na disputa de narrativas em tempo real.

O terceiro e mais ambicioso colóquio - Os Mil Nomes de Gaia: do Antropoceno à Idade da Terra - organizado por Danowski, Viveiros de Castro e Juliana Fausto em setembro de 2014, já numa dinâmica institucional marcada pela escassez de financiamento, trouxe - ao longo de uma semana, entre gravaçóes e viagens de avião - as vozes de Silvia Rivera Cusicanqui, Ailton Krenak, Elizabeth Povinelli, Donna Haraway, Isabelle Stengers, Bruno Latour e muitas mais. Também estiveram lá dois pesquisadores que participaram em terraTERRA, Rodrigo Nunes e Alexandre Nodari. O título do evento atualizava na imaginação pública o cristianismo múltiplo e terceiro-mundista de Glauber Rocha: A Idade da Terra, seu último filme.

Menciono esses três colóquios prévios e parcialmente conectados entre si para situar - se não essa chamada a pensar a habitação da terra, que prolonga nas páginas da Alea um colóquio sediado na Casa Rui, e se não uma pequena sobrevivência de gestos reflexivos em torno da questáo - ao menos algumas trilhas conceituais que gostaria de visualizar em um mesmo quadro. 
Afrouxando um modo de ler que acentua radicalmente a distinção, podemos imaginar que, apesar das divergências, os encontros compartilham um mínimo desejo: tensionar as ações do reformismo então existente no sentido de um reformismo forte. ${ }^{2}$ Desejo de um mínimo múltiplo comum, cada vez mais improvável: vistos retrospectivamente e em conjunto, os arquivos dos três encontros - ou quatro, se aceitarmos que a coloquialidade das ruas não nega os colóquios da Casa - parecem registrar, sintomaticamente, uma brecha se fechando. Todos foram acontecimentos enunciativos atravessados pela percepção de um descompasso que as decisóes governamentais indicavam estar dispostas a alargar mais e mais. Em um ritmo, diretrizes de desenvolvimento definidas pela aposta na aceleraçáo de um crescimento lastreado na ampliação do extrativismo, com as energias voltadas à tecnologia de um setor agroexportador. Em outro ritmo, nada desprezível, mas bastante menor em recursos e visibilidade, políticas públicas promissoras que poderiam fortalecer circuitos de cooperações locais e continentais. Se os fatos institucionais na sequência de 2014 têm sido vividos sob o signo pesado do desmonte, obrigando a uma experiência ansiosa e angustiada dessa topologia contraditória do Estado que também somos, a interrogaçáo que caberia deixar como ambiência para este texto é sobre o que lemos hoje no descompasso. São apenas variaçôes no já conhecido imaginário dos dilemas estratégicos de economias periféricas e dependentes no capitalismo global? Há algo diferente disso para ser lido?

Uma provocação de leitura como a de Josefina Ludmer [2010], pautada pelo abandono da autonomia distintiva dos discursos e por sua entrada definitiva nas redes biopolíticas de extração do valor, no campo minado da imaginação pública, nos coloca um desafio difícil: assumir a coimplicação de macropolítica e micropolítica. Para uma chamada a pensar poesia e latinoamericanidade que partisse da relaçáo com a terra, isso evocaria uma série de não-ditos. Mediadas pelas pedagogias de leitura, todas as intervençôes subscrevem alguma relação entre poemas e instituições. Cada uma delira um vínculo possível ou impossível entre poemas e políticas públicas. Cada uma acredita na possibilidade ou na impossibilidade de usos estratégicos do Meio Ambiente e da Cultura no tensionamento político da exploração dos territórios e do trabalho. Cada uma remete a diferentes pesos dados, por cada pesquisador/a, à sua autonomia relativa ou à sua transversalidade potencial. Quais modos de ler definem o possível de cada intervenção? O que se dá a ler no arquivo?

2 Contornando a oposição principista entre instituição e transformação, ao refletir sobre a conjuntura, Rodrigo Nunes (2014) dizia: "A radicalidade que náo encontrar formas de positivar pelo menos aquilo que lhe proporcione uma base a partir da qual continuar se constituindo, ou se dissipará, ou se isolará num narcisismo mais apaixonado por si mesmo do que pelas mudanças que é capaz de promover no mundo”. 
Com alguns poemas e esse punhado de perturbaçóes em tensão, gostaria de tentar articular um pensamento ao redor de uma impressão bastante simples: o momento de ameaça e desmonte da hegemonia discursiva que valida neste território a Constituição de 1988 (e seu horizonte de direitos) nos instiga a revisitar as alianças que possibilitaram a montagem; o agenciamento coletivo que se implicou naquele processo constituinte, movido por desejos de restituição e instituição. ${ }^{3}$ Para interrogar uma relação entre pedagogias de leitura e práticas extrativas, considerando o desafio de Ludmer, proponho passar por algumas notas fragmentadas sobre a conjuntura teórica em que emerge a prática autodeclarada do discurso latino-americano, via Silviano Santiago, em dois momentos (1971/1978). Pensando um modo de ler como uma intervenção sobre a ordem desse discurso e sobre as atividades que ele busca organizar, no subsolo das pequenas diferenças, tento realocar alguns bloquinhos do bloco histórico que nos permitiu herdar, inclusive, esse lugar compartilhado de enunciação. Tentativa situada, mínima ou enorme: de entender onde estamos, como nos lemos, em que tom nos desentendemos e em que terreno fincamos nossas trajetórias de estudo na trilha da institucionalização de certos modos de ler.

\title{
Ler a situação
}

Uma entrada possível seria pelo fim de um poema recente de Marília Garcia, publicado em sua página no blog da companhia das letras. Ele atualiza um enunciado de 1974 e termina desorientado:

\author{
penso num poema do cacaso \\ e na américa latina do futuro \\ que um dia ele quis imaginar \\ olho para a minha filha \\ e, juntas, olhamos para \\ esta américa latina \\ do futuro \\ estamos num túnel de fumaça \\ e não consigo ver o que aconteceu
}

(GARCIA, 2019)

\footnotetext{
3 Em abril de 2016, na mesma Casa de Rui Barbosa, Manoel Ricardo de Lima (2016) lia "as cinzas de Gramsci”, poema de Pasolini, e comentava: "Toda proximidade e contágio seriam quase um relato do desamparo e do desespero que, num ódio formal e ordinário, se expande entre nós nesse momento nada singular e que nos aparece sempre como se visto de cima em câmera de bico: quando a terra é apenas uma cabeça e quando a democracia (ainda) não é suficiente, ou quando a democracia, se uma invenção radical, é muito mais um desejo de democracia”.
} 
Imagem da América Latina como lugar de inconstância democrática; imagem turva diante da ascensão da extrema-direita - não sorridente, nem feliz. A clivagem latino-americana, poderíamos pensar, não seria entre fim e começo, mas entre rupturas e rituais de recomeço: era por isso que no pósditadura, em 1985, Ludmer discordava de Walter Mignolo sobre a possibilidade de um discurso teórico sistemático ${ }^{4}$. O descontínuo tem sido uma exigência institucional que os golpes não cessam de reimpor (e que os poemas não desistem de recompor). Mas porque queremos deixar mais rastros num diálogo iniciado, falo de Marília Garcia também por lembrar que há pouco mais de um ano, convidado a pensar sobre poesia e latino-americanidade, Marcos Natali nos falava dos movimentos da terra em um de seus poemas. ${ }^{5}$ Recorrendo à capital do México, ele contava dos ensaios coletivos que acontecem em cidades habituadas aos terremotos: nesses testes de antecipação das ruínas, na "experiência da iminência do fim", em um presente que se experimenta como o estrato no qual escavamos e extraímos nossos vestígios de vida ${ }^{6}$, a sismologia deseja ser um estudo do futuro, propiciando pequenas suspensóes do cotidiano que reativam o valor público dos encontros.

Se conseguirmos ver algum valor de encontro nessas posiçôes autorreferenciais de leitura, diria que Marília Garcia vem convocada aqui como índice de uma boa quantidade de inquietaçóes comuns a tentativas de pensar, hoje, o lugar público do poema; as de alguém que, ao longo dos últimos quinze anos, tem contribuído na difusáo de um debate interessado em uma possível literalidade dos efeitos de leitura. Em suas pesquisas, o discurso literário - menos preocupado com a afirmação de sua autonomia distintiva e mais habituado ao alargamento e à indefiniçáo - busca pensar como os deslocamentos da atenção incidem nas tensóes dêiticas; inclusive, as de um lugar e de um tempo latino-americanos e nublados. Importam, para ela, as perguntas sobre a eficácia dos modos de ler. Um dos momentos em que joga com esse potencial teórico e pedagógico da interrogação testa duas proposiçóes: o que faz um poema é o timing e cada poemal traz a medida de uma época (GARCIA, 2018, p. 71-80).

A aceitação do experimento - colocar o "poema no tubo de ensaio" - nos leva a uma variação constante nas tentativas de organizar a leitura da

4 Para uma apresentação e leitura dessa divergência, ver Gerbaudo, 2015.

5 Faço referência à apresentação de Natali na mesa-redonda Poesia e latino-americanidade, organizada pelas mesmas organizadoras deste dossiê (com Viviana Gelado) na Universidade Federal Fluminense em 28 de junho de 2018, a que se dava continuidade no II Colóquio Habitar a Terra: poesia e latinoamericanidade. Ver Natali, 2019, para uma versão ampliada daquela apresentação.

6 Ver Antelo, 2016a, p. 22. 
situação, oscilando entre um letramento literário e um letramento digital ${ }^{7}$. Escrevendo sobre o segundo livro de Ana Estaregui, Coração de boi, Garcia se mostra interessada, por exemplo, na relaçáo entre um pensamento materialista e uma subjetivação indeterminada. O livro distribui a investigação dessa relação em uma série de 72 poemas numerados, como este, o 30 :

\author{
alguns cavam buracos monumentais \\ e neles persistem como retroescavadeiras \\ buscando o ponto preciso \\ de onde jorra o petróleo \\ o concentrado puro, outros \\ estudam modos de conquistar o espaço \\ achar locais amplíssimos de outra lógica \\ para, quem sabe, reconfigurar tudo \\ outros insistem em ficar olhando \\ as mesmas palavras de sempre \\ e esperando que surjam delas \\ barcos, vozes, ou outras coisas que flutuem \\ (ESTAREGUI, 2016, p. 40)
}

Em uma primeira nota, penso que na economia das práticas (escavação, estudo, espera), o poema sugere uma relaçáo entre usos da terra e pedagogias de leitura. Podemos ler, de partida, a percepção de que existe uma prática extrativista de leitura: a busca da pérola jorrando de dentro do poema, como acho que escutei Luciana di Leone dizer algum dia, em aula. Logo, segue com uma sutil desconfiança da utopia, da reconfiguração total derivada de uma conquista redentora. Ao final, talvez caiba lermos o mesmo que Natali (2019, p. 304) lia com Garcia: "o poema se torna um tratado sobre a espera e o porvir, ele próprio pertencendo aos gêneros da promessa e da profecia”.

Interessante notar como essa leitura de Natali-que registra discretamente o diálogo com uma ex-aluna, Mariana Ruggieri (2018) - faz lembrar a conclusão de um texto anterior no qual imaginava exatamente uma prática pedagógica que questionasse suas premissas de progresso e adiasse o fim: como o poema, a aula professada deseja "uma resposta que seja uma promessa de continuidade e a manifestação da vontade de continuar a pensar junto" (NATALI, 2017, p. 33) ${ }^{8}$. Assim, repensando extração e estudo, podemos encontrar - em um mesmo estrato arqueológico - os questionamentos

7 Sobre as suturas entre letramentos, ver Link, 2015, p. 118-125.

8 Agradeço a Aline Rocha a sugestão de leitura desse texto e as conversas relacionadas. 
sobre as pedagogias do poema ${ }^{9}$ e as refraçóes memoriais de uma pedagogia em que o traço latino-americano seja uma posição ética, como sugeriu di Leone (2018, p. 75). Uma pedagogia que, sendo testemunha da eficácia de um aprender defasado no tempo e de um ensino que não coincide com sua enunciação, se lança em busca de outros gestos, nos quais possam confluir desconstrução e autorização.

Abertas as séries do arquivo e das pedagogias, volto então ao poema de Estaregui. Guardo essas três percepçóes de leitura: que na relaçấo entre materialidade e indeterminaçáo o poema monte uma cena que contrasta diferentes modos de ler, com os pronomes coletivos ("alguns", "outros", "outros"); que o poema possa ser lido simultaneamente como uma proposta de suspensão (literária tanto quanto literal: um problema para permanecer com; uma aporia) do extrativismo $e$ das utopias totalizantes; e que nos convide enfim a atentar à deriva do sentido... isso é já mais que o suficiente para que nos apoiemos em sua medida daqui até o fim, interrogando um vínculo entre o arquivo e a terra no discurso latino-americano. Entre as veias abertas e as formas abertas.

\section{Veias abertas, canteiro de obras}

Uma reflexão sobre o discurso latino-americano poderia começar lembrando que o ensaio de Silviano Santiago que instaura essa discursividade, apresentado inicialmente em 1971, ano d'As veias abertas da América Latina, de Eduardo Galeano, está publicado em livro de 1978 que tem no subtítulo a ideia de dependência cultural. Sustentando uma crítica da extrapolação da teoria da dependência geopolítica às práticas literárias, ele se afirma a favor da "grilagem" 10 do capital cultural, recusando um modo de ler que condena uma literatura nos trópicos à referência de fontes e influências europeias. $\mathrm{O}$ estruturalismo econômico latino-americano participa, ali, como fundo negativo do discurso. É um material lido através de deslocamentos que emergem com a epistemologia histórica, em uma conjuntura teórica que desativa a topologia estrutural, mas não arrisca fundir as chamadas infraestrutura e superestrutura. Essa literatura em um continente perfurado por séculos de extração, portanto, aparentemente deseja uma distância relativa aos usos da terra. Não há entre as duas práticas, a princípio, uma relação estratégica. Mas como, efetivamente, Silviano lia a teoria da dependência? Como interrogar uma relação entre formação discursiva e práticas extrativas?

Em 1977, ano brutal na Argentina e na Itália, sai a segunda edição da revista Contexto, dedicada à América Latina. Os eixos "movimento operário

9 Ver Moriconi, 2002.

10 Ver Santiago, 1984. Em texto de 2003, a metáfora é atualizada para uma "estética do usucapião". 
- tipologia política - literatura” eram anunciados na capa, que mostrava um mapa da América do Sul onde as fronteiras do território brasileiro com os países vizinhos apareciam suturadas, como se a nos lembrar visualmente da operação clínica necessária para uma perspectiva regional, impedindo um afastamento tectônico. A revista trazia uma resenha de Silviano ao livro mais recente de Florestan Fernandes, uma leitura da Revolução burguesa no Brasil, de 1975: mesmo ano da edição brasileira do clássico de Mariátegui - Siete ensayos sobre la realidad peruana, de 1928 - que recebeu um prefácio de Florestan. Essa resenha havia sido lida no ano anterior à publicação em revista, durante um evento homenageando Florestan na Universidade do Texas: 1976, mesmo ano em que Ruy Mauro Marini, depois de escrever a Dialética da dependência, tendo vivenciado também o golpe contra Allende, defendia, em estudo publicado no exílio mexicano, que o reformismo funcionava como antessala da contrarrevolução. A resenha de Santiago (2018), enfim, elogiava em Florestan a operação de uma lógica da diferença na recepção das teorias sociológicas do desenvolvimento desigual, enfatizando as forças progressistas que "tentavam neutralizar a dependência". Mas o leitor nascido nas Minas Gerais notava uma importante "ausência na análise" das práticas discursivas escolhidas por Florestan, que implicava em lacunas na percepção da densidade política do período colonial: a economia da mineração.

O apontamento de Santiago (2018, p. 309) enfatiza os contornos históricos da leitura: marcado pelo pessimismo de uma conjuntura ditatorial pós-1964, sem vislumbrar saídas estruturais, descrente na "possibilidade de se organizar uma utopia revolucionária que tom[asse] e envolv[esse] a realidade numa gigantesca e aberrante racionalidade", Florestan projetaria retrospectivamente essa impossibilidade de ruptura, afirmando uma metodologia circunscrita pelo possível concretizado e deixando de lado o interesse pelo "estudo da relação precária" entre discurso utópico e realidade, "na sua circularidade quase imaterial e na sua economia de derrota". Para Santiago, porém, caberia considerar a "força progressista" e propulsora da organização germinal contra a exploração extrativista: ali "surgem os discursos mais audaciosos do ponto de vista revolucionário”. A reabertura do arquivo das insurreiçóes mineiras fica como sugestão.

Quando escreve sobre o "Silviano Santiago leitor de poesia" para um evento em sua homenagem na Casa Rui, Celia Pedrosa (2014, p. 217) registra os traços da escavação e do sintoma: sintoma da necessidade de questionar as pedagogias do poema; difícil escavaçáo de um entre-lugar que desloque dicotomias. Uma busca na discursividade instaurada por Santiago passaria, entâo, por experimentar e destacar a historicidade de seus modos de ler. E se 
uma epígrafe do ensaio lido em 1971 apontava para a Arqueologia do saber, o gesto que o conclui traz precisamente a leitura sintomal, apresentada em Lire le Capital: "a técnica de leitura e de produção dos escritores latinoamericanos se parece com a de Marx, de que nos falou recentemente Louis Althusser" (SANTIAGO, 2000, p. 25-26). ${ }^{11}$ Produzindo um retrato do trabalho de Marx em seu canteiro ("estamos diante de um leitor, que diante de nós e em voz alta lê"), a contribuição deixada por Althusser à epistemologia materialista - e a seus alunos - ressalta que a leitura é uma prática. Se os textos nem sempre conseguem operar o deslocamento desejado, deixam traços desse desejo em sua materialidade de pensamento em movimento: levar a sério esses traços implica também valorizar as descontinuidades em uma história do conhecimento interessada na contingência. É com essa pedagogia da leitura - lacunar, cooperativa e ética - que Silviano lê, em 1976, o livro de Florestan, apontando caminhos para levar em outras direçóes seu desejo de uma melhor posição de leitura, sugerindo outra relação possível entre discurso e economia.

A discursividade ensaiada na primeira metade da década de 1970 nos ensina, portanto, um modo sintomal de ler o arquivo $e$ o presente em que posicionamos nossa leitura, expondo um desajuste permanente: uma movimentaçáo simultânea das condiçóes de conhecimento e de desconhecimento. Um retorno ao texto matricial pode servir como lembrete da possibilidade de reembaralhar as tensóes entre diferentes pedagogias de leitura do tempo presente, invertendo, com a prudência possível, a hierarquia das cartas de causa e efeito, ou de impossível e real, testando outros gestos de disposição dos letramentos que coexistem conflituosamente em uma conjuntura.

Ao ler o "entre-lugar do discurso latino-americano" como documento de época, Jorge Wolff (2016, p. 46-47) notou que existem pequenas mas sintomáticas metamorfoses entre a primeira versão do início dos anos 1970 e a publicada em 1978, mas assinada 1971. Conforme se vislumbrava no horizonte uma reabertura institucional, o texto respondia com um afastamento discursivo da revolução, do radicalismo e do campo de batalha, apontando o foco para a micropolítica. $\mathrm{O}$ ajuste das posiçóes de leitura segue com a continuação do debate sobre a dependência cultural nos primeiros textos de Vale quanto pesa, escritos entre 1978 e 1981, após a publicação de Uma literatura nos trópicos, em uma reiterada oposição conceitual entre populismo e nacional-

11 A referência à leitura sintomal é retomada em "Análise e interpretação", de 1975, o último texto em Uma literatura nos trópicos. 
popular, texto populista versus antropológico-literário. Naquele momento de Anistia, os modos de ler a literatura, a sociologia e o Estado se (con)fundem. 1978, afinal, seria o ano arquioficial da fundação de um novo Partido dos Trabalhadores, que contaria com Florestan entre seus quadros e que, segundo Margaret Keck (1991), instauraria precisamente uma lógica da diferença na política institucional republicana, uma alternativa ao que entâo se entendia como populismo. Ali, a dupla Foucault-Althusser, que amparava a reflexão de 1971 sobre o discurso, retorna por outros meios: Santiago (1982, p. 18) se implica abertamente na imaginaçáo constituinte do socialismo democrático, um caminho defendido também em 1978 por Nicos Poulantzas, através de uma leitura de Althusser bastante atravessada pela microfísica de Foucault. A materialidade dos textos guarda a possibilidade (imprevisível, incontrolável) de uma convergência nas tarefas de desconstruçáo dos fundamentos e de reorganização política.

\section{Extrações no território da língua}

A potência constituinte se afirma ao autorizar outros começos, que são sempre pontos contingentes de articulação em uma rede transnacional de práticas e discursos; pontos em uma série que desdobra a singularidade de um acontecimento. ${ }^{12}$ Basta um acontecimento para reembaralhar as coordenadas: a guerra del agua na Bolívia. Ao se iniciar impulsionado pela energia dos movimentos sociais, o último ensaio coletivo de uma governamentalidade latino-americana parece ter explicitado que a distinção Natureza/Cultura é móvel, abrindo o dossiê da possibilidade de uma imaginaçáo pós-extrativista no interior da forma-Estado. As ocasiôes em que a imaginação pública se assume constituinte permitem ver de que modo a atualização dos posicionamentos jurídicos se equilibra entre as ficçóes de origem e as brechas nos contraídos horizontes de um modo de reproduçáo que administra - orgulhosa e lucrativamente - os custos de uma gestão permanente das catástrofes. No fechamento das brechas, o ensaio coletivo impulsiona novas dependências geoeconômicas, reativando o debate da década de $1970 .{ }^{13}$ Como atualizar aqui o deslocamento operado por Silviano Santiago? Ou melhor, como assumir o desafio de Josefina Ludmer e pensar uma coimplicação de micro e macropolítica, sem desvincular discurso e economia?

Quando em 2005 aparece um livro de Antonio Negri e Giuseppe Cocco que atualiza o debate sobre a dependência em um eixo biopolítico, ambientado naquela esperançosa conjuntura latino-americana, pós-ditaduras

12 Ver Antelo, 2016b.

13 Ver, por exemplo, Svampa, 2019. O catálogo que vem sendo montado pela editora Elefante é já um arquivo significativo do modo como esta bibliografia chega ao território de língua portuguesa. 
e Glob(AL), Verónica Gago entrevista o segundo para o jornal Brecha, que teve Eduardo Galeano entre seus fundadores. A conversa registrava uma aposta na abertura dos governos às reformas impulsionadas pela pressão dos movimentos populares, que poderia ser lastreada na cooperação continental e numa governança pós-nacional. Um rumo para a interdependência. Uma porta estreita. Nos mesmos anos, na Universidad de Buenos Aires, Gago assistia aos seminários em que Ludmer antecipava aquele que viria a ser seu último livro, Aqui América Latina, operando, através de alguns conceitos (imaginação pública, território da língua) uma atualização das teorias materialistas da leitura ${ }^{14}$. Embora não tenha mencionado especificamente o livro de Negri e Cocco, Ludmer rastreava as movimentaçóes na referencialidade do território (o Aquí, a dêixis) fazendo uso das mesmas perspectivas teóricas desenvolvidas pelos exilados do operaísmo italiano de 1977, que apontavam para as transformaçóes nas modalidades de exploração, prolongando as reflexóes de Althusser, Foucault e Deleuze sobre os dispositivos de disciplina e controle.

Propondo pensar um território da língua atravessado por conflitos (re) produtivos e memoriais, Aqui América Latina marcava uma aproximação ética entre a dimensão linguística e cooperativa da imaginação pública e um subsolo material, de uso comum, naturalizado, análogo à água e ao petróleo. $\mathrm{Na}$ economia das trocas linguísticas contemporâneas, ambos - território e língua - são alvos da extração. Assim, na imbricação das concessốes das terras e dos subsolos, Ludmer (2013, p. 109-113) articulava a crítica do aprofundamento do extrativismo e de uma estrutura fundiária crescentemente privatizada, ajudando-nos a visualizar em um mesmo diagrama alguns eixos de uma recomposição emergente no discurso latino-americano, entre escavaçóes forenses, feminicídios e conflitos em territórios indígenas: o território é o ponto nodal de um violento impasse, que afeta as alianças políticas contemporâneas.

$\mathrm{O}$ agenciamento territorioafecto sugerido por Ludmer apontava, então, para um deslocamento nos modos de ler a dependência e a extração: de um eixo analítico para um traço ético e biopolítico, imanente à subjetivação. É precisamente esse movimento que os estudos de sua ex-aluna Verónica Gago levam adiante. ${ }^{15}$ Seguindo suas leituras, podemos aproximar os conceitos pensados por Ludmer e o corpo-território pensado pelos coletivos feministas e por Gago $(2020)^{16}$. Uma aliança discursiva latino-americana, hoje, parte

14 Essa ênfase nos modos de ler é uma deriva de conversas sobre as leituras do último livro de Ludmer com Leonardo Vilela (cf. a conclusão de sua dissertação, 2019), que também me emprestou os livros de Estaregui e Ludmer: devo a ele boa parte deste texto.

15 Em entrevista com Ludmer, Gago (2016) comenta brevemente os cursos assistidos à época da concepção de Aqui América Latina.

16 Agradeço a Clarice Goulart as conversas relacionando os livros de Gago. O desenvolvimento de um conceito ampliado de extraçáo, retomado em $A$ potência feminista, foi inicialmente desenvolvido em parceria (2015) com seu coorientador de tese, Sandro Mezzadra. Interessante notar, ainda, que Gago (2020, p. 
dessa composição biopolítica feminista, como anuncia o título da plaquete bilíngue de Priscilla Menezes, Eu vou invadir os latifúndios que cercaram a minha carne, publicada em 2019 pela editora nadifúndio.

Eu vou invadir os latifúndios... começa pela busca de um modo de composição orgânico: deseja "um poema que fosse vermelho", com "cheiro de ferro", como as ferramentas e "as coisas de preparar o chão, os textos/ as matrizes, de pôr o mundo abaixo/ e depois acima, revirar a terra, fértil [...]"; e desse modo deseja um poema que "também seja feitiço", com olhos que enxergam "aquilo que trai os pactos/ entre as causas e os efeitos/ aquilo que cria novas causas/para efeitos improváveis/ aquilo que esgarça as probabilidades/ e as insurgências/ aquilo noturno que pertence aos despossuídos/ aquilo que é nossa única chance/ a revolução" (MENEZES, 2019, p. 8).

A tentativa de experimentar analogias entre chão e página aparece também na série de Estaregui, como questão:

o que aconteceria aos poemas

se neles acrescentássemos matéria sólida

se, como nas cançóes,

onde há som voz cordas de metal

depositássemos

alguma seiva e um pouco de ar?

se lançássemos sobre eles

um punhado de sementes

e entáo nos sentássemos para esperar

por muito tempo

algum movimento sutil

alguma oscilação inaudível

uma dobra só que fosse

sobre a página um pequeno rumor

de qualquer tipo, capaz de levantar

do chão branco alguma voz

o que aconteceria aos poemas

se pudéssemos esperar um pouco mais

(ESTAREGUI, 2016, p. 65)

146) fala de uma "leitura sintomática" de Marx feita por teóricas feministas, atualizando a percepção de Althusser sobre a leitura sintomal que Marx faz dos economistas liberais. 
Aqui, a espera que concluía nosso poema-guia retorna acompanhada de uma especulação que busca recuperar um ciclo de organicidade, para que algo cresça distinto das leituras que sufocam: dilatar o tempo, adiar o desfecho (outro nome para o desejo?) - permitir que a série continue. A interrogação volta em outros pontos, e seus gestos de reciclagem não parecem metafóricos: falam da matéria linguística, do ar, da respiração, testando um performativo que retrai a extração no território da língua, explicitando os vínculos desejados e rejeitando os indesejados, escavando um compasso etológico por outras estratégias de leitura ${ }^{17}$ :

\author{
abrir múltiplos buracos \\ na terra sólida \\ para ver os caminhos das minhocas \\ escavados em ordens estratégicas \\ de entradas e saídas de ar \\ nadar nadar, cavar \\ estradas e saídas de emergência \\ $[\ldots]$
}

(ESTAREGUI, 2016, p. 69)

"Um inseto cava/ cava sem alarme/ perfurando a terra/ sem achar escape.// Que fazer, exausto,/ em país bloqueado,/ enlace de noite/ raiz e minério?": Ao ler o Áporo de Carlos Drummond de Andrade interessado em uma "disponibilidade ética", Raúl Antelo (2003) também lembrava Josefina Ludmer e sua mobilização das leituras pós-operaistas do capitalismo para pensar a bloqueada conjuntura argentina de 2002, afirmando com ela a possibilidade de uma subjetivação pós-nacional que se encenasse, precisamente, na leitura da aporia. Do mesmo modo, quando perguntava como explorar um arquivo, Antelo (2016c) sugeria que Ruben Darío ensaiava arqueologicamente uma "poética democratizante" ao construir "o próprio processo de leitura". $\mathrm{O}$ arquivo pode ser lido como uma natureza-morta. Isso nos diria Darío em seu poema Tutzecotzimi, publicado em 1916: "que essas caixas, esses arquivos que são os poemas, não apenas contêm verdade, mas são a própria verdade, e, nesse sentido, há verdade, porém, ela está deslocada e é necessário rearmá-la a posteriori [...]" (ANTELO, 2016c, p. 17).

17 Ver também, nesse sentido e além, a reflexão de Rafael Zacca (2019) a partir de outras duas poetas, Ana Carolina Assis e Marília Floôr Kosby. 
O poema .30 de Estaregui, que rearma um arquivo de pedagogias da leitura, convoca também a abrir mão do desejo de profundidade, distanciandose da prática de leitura-extração que deixa "buracos monumentais". Mas faz isso sem deixar o poema intocado. Ressoando as "sementes crioulas" com que o poema de Menezes (2019, p. 18) - também interessado em "outra lógica" - conspira, Estaregui nos convida a testar a leitura como compostagem. O "esperar" a que convocam os poemas de Coração de boi náo se equilibra, portanto, na contemplaçáo que reitera um valor da obra já feita. Se ler é uma amarração (fixão) de sentido com o que recusa incessantemente a representação ${ }^{18}$, ler, abrir a linhagem do poema e ver junto dele a série que liga a caixa preta dos recentes crimes socioambientais nas Minas Gerais e os séculos de arquivo metálico do extrativismo é também reavaliar a extração do valor - nesse curto tempo em que o poema se des(d)obra em série.

Para preencher a série de modos de ler implicada no poema .30, poderíamos então repensar as pedagogias coletivas de leitura, esses modos que não somos, ou que não queremos ser, ou que eventualmente podemos também ser: "alguns cavam buracos monumentais/ e neles persistem como retroescavadeiras"; "outros/ estudam modos de conquistar o espaço"; "outros insistem em ficar olhando/ as mesmas palavras de sempre". Nessa descrição objetiva, os modos de ler são inseparáveis de uma relação com o arquivo e com a terra: o poema se faz ele mesmo o dispositivo, anteparo e preparação da ação de leitura, onde coincidem subitamente a metateoria e a micropolítica; um canteiro em que se distribuem as caixas com os arquivos dos gestos coletivos e das pedagogias do poema.

Se a clivagem latino-americana tem sido entre interrupçóes e rituais de recomeço; se a instabilidade, a descontinuidade, a vacilação... se todas são prerrogativas de uma historiografia de catacumbas feita a golpes de Estado, elas não o são menos que as marcas de uma topografia desfeita a golpes de topadoras. Disputando a possibilidade do comum em um pedaço de terra - o de uma Universidade, Fundação ou imaginação pública - o discurso latino-americano atualiza em nós uma memória de gestos que se opóem ao extrativismo. A que se permite acolher o não saber. A dimensão pedagógica dos poemas aqui trazidos estaria em dizer algo assim: que enquanto a história se mostrar como uma sucessão infinita de hegemonias, algum agenciamento ou aparição surgirá das alianças de letramentos que fazemos agora.

18 Ver Antelo, 2015, p. 102: “é uma questão de fixão, uma amarração do sentido com aquilo que não cessa de não se representar”. 


\section{Referências}

ANTELO, Raúl. A aporia da leitura. Ipotesi, Juiz de Fora, v. 7, n.1, p. 33-45, 2003.

ANTELO, Raúl. "A cena arquifilológica”. In: ANDRADE, Antonio et al. (orgs.). Caminhos do hispanismo: vozes críticas, tendências teóricas. Rio de Janeiro: 7 Letras, 2015, p. 98-115.

ANTELO, Raúl. A ruinologia. Florianópolis: Cultura e barbárie, $2016 a$.

ANTELO, Raúl. El diseño de la máquina entre-lugar. Cuadernos de CILHA, v. 17, n. 1 , p. $29-47,2016$ b.

ANTELO, Raúl. Como explorar um arquivo?. Boletim de pesquisa NELIC, Florianópolis, v. 16, n. 25, p. 3-31, 2016 c.

DI LEONE, Luciana. Não entender: o canteiro de obras. A pedagogia (im)possível. Boletim de pesquisa NELIC, Florianópolis, v. 18, n. 29, p. 71-84, 2018.

ESTAREGUI, Ana. Coração de boi. Rio de Janeiro: 7 Letras, 2016.

GAGO, Verónica. Hacia una nueva democracia. Debate sobre América Latina. Entrevista de Verónica Gago a Giuseppe Cocco. Brecha, 21 mai. 2006. Disponível em: <http://pvp.org.uy/cocco.htm>

GAGO, Verónica. La profesora. Entrevista de V. Gago a Josefina Ludmer. Las 12. 15 abr. 2016. Disponível em: <http://pagina12.com.ar/diario/suplementos/ las12/13-10503-2016-04-15.html>

GAGO, Verónica. A potência feminista: ou o desejo de mudar tudo. Trad. Igor Peres. São Paulo: Elefante, 2020.

GAGO, Verónica; MEZZADRA, Sandro. Para una crítica de las operaciones extractivas del capital. Patrón de acumulación y luchas sociales en el tiempo de la financiarización. Nueva Sociedad, Buenos Aires, n. 255, p. 38-52, 2015.

GARCIA, Marília. Continuar continuar: sobre o livro Coração de Boi (7 Letras, 2016), de Ana Estaregui, por Marília Garcia. A bacana, 11. abr. 2018. Disponível em: <http://abacana.com/oficial/continuar-continuar-sobre-o-livro-coracao-deboi-de-ana-estaregui-7letras-2016-por-marilia-garcia>

GARCIA, Marília. parque das ruínas. São Paulo: Luna Parque, 2018.

GARCIA, Marília. História natural. In: Blog da Companhia, 30 ago. 2019. Acesso em: <http://blogdacompanhia.com.br/conteudos/visualizar/Algo-de-bom-nomundo-da-poesia>

GERBAUDO, Analía. Funciones y sentidos de la Teoría literaria. Una conversación entre Josefina Ludmer y Walter Mignolo. Badebec, Rosario, n. 5, v. 3, p. 155$183,2013$. 
KECK, Margaret. PT, a lógica da diferença: o Partido dos Trabalhadores na construção da democracia brasileira. São Paulo: Ática, 1991.

LIMA, Manoel Ricardo de. É antes o fim de um mundo. Passagens, Fortaleza, v. 7. n. 2, p. 87-96, 2016.

LINK, Daniel. Suturas. Imágenes, escritura, vida. Buenos Aires: Eterna Cadencia Editora, 2015.

LUDMER, Josefina. Aqui América Latina: uma especulação. Trad. Rômulo Monte Alto. Belo Horizonte: Editora UFMG, 2013 [2010].

MENEZES, Priscilla. Eu vou invadir os latifúndios que cercaram a minha carne I invadiré los latifundios que rodearon mi carne. Fortaleza: nadifúndio, 2019.

MORICONI, Italo. Horizontes formativos, lugares de fala: Antonio Candido e a pedagogia do poema. Gragoatá, Niterói, n. 12, p. 47-62, 2002.

NATALI, Marcos. Autobiografias do começo de uma aula. Magma, São Paulo, n. 13, p. 19-33, 2017.

NATALI, Marcos. Tremor tremor. Meteöro - revista de poesia, n. 1, São Paulo, p. 297-315, 2019.

PEDROSA, Celia. Silviano Santiago leitor de poesia. In: PEDROSA, Celia; DIAS, Tania; SÜSSEKIND, Flora (orgs.). Critica e valor: Uma homenagem a Silviano Santiago. Rio de Janeiro: Fundação Casa de Rui Barbosa, 2014, p. 209-218.

NUNES, Rodrigo. Generación, acontecimiento, perspectiva. Pensar el cambio a partir de Brasil. Nueva Sociedad, Buenos Aires, n. 251, p. 42-54, 2014.

RUGGIERI, Mariana. Variaçóes da literatura. Tese de Doutorado (Teoria Literária e Literatura Comparada), Universidade de São Paulo, São Paulo, 2018.

SANTIAGO, Silviano. Uma literatura nos trópicos: ensaios sobre dependência cultural. 2a. ed. Rio de Janeiro: Rocco, 2000 [1978].

SANTIAGO, Silviano. Vale quanto pesa: ensaios sobre questóes político-culturais. Rio de Janeiro: Paz e Terra, 1982.

SANTIAGO, Silviano. Borges segundo Silviano Santiago. Folhetim, São Paulo, p. $2,19 / 08 / 1984$.

SANTIAGO, Silviano. "O trabalho do alfaiate", In: Ora (direis), puxar conversa!: ensaios literários. Belo Horizonte: Editora UFMG, 2006. p. 281-285 [2003].

SANTIAGO, Silviano. A revolução burguesa. Sociologia \& Antropologia, Rio de Janeiro, v. 8, n. 1, p. 299-312, 2018. 
SVAMPA, Maristella. Las fronteras del neoextractivismo en América Latina. Conflictos socioambientales, giro ecoterritorial y nuevas dependencias. Guadalajara: CALAS, 2019.

VASCONCELOS, Mauricio S. Espiral Terra: poéticas contemporâneas de língua portuguesa. São Paulo: Annablume, 2013.

VILELA, Leonardo. A deriva como procedimento estético: uma cartografia afetiva de práticas artísticas e poéticas no cenário contemporâneo brasileiro. Dissertação de Mestrado (Estudos de Literatura), Universidade Federal Fluminense, Niterói, 2019.

WOLFF, Jorge. Telquelismos latino-americanos: a teoria crítica francesa no entre-lugar dos trópicos. Rio de Janeiro: Papéis Selvagens, 2016.

ZACCA, Rafael. O coletivo como floresta e a pedagogia da imanência. Poiésis, Niterói, v. 20, n. 33, p. 55-74, 2019.

Vinícius Rodrigues Ximenes. Doutorando em Estudos de Literatura pela Universidade Federal Fluminense com bolsa CAPES, mestre em Estudos de Literatura pela Universidade Federal Fluminense, com bolsa CNPq (2019) e bacharel em Ciências Sociais pela Universidade Federal do Rio de Janeiro (2016). Integra o grupo de pesquisa Pensamento teórico-crítico sobre o contemporâneo.

E-mail: viniciusximenes@id.uff.br 